\title{
Grau de deterioração socioeconômico e ambiental como ferramenta para gestão territorial em uma microbacia hidrográfica
}

Pela legislação brasileira, a bacia hidrográfica é a unidade territorial para implementação da Política Nacional de Recursos Hídricos. Nesse sentido, a gestão dos recursos hídricos, de valor inestimável à sociedade, deve ser feita utilizando práticas que mantenham o equilíbrio ambiental e o manejo adequado do uso das terras nas bacias hidrográficas, sendo essenciais para a manutenção dos recursos naturais e da sociedade em geral. Este estudo teve como objetivo determinar unidades deteriorantes na microbacia hidrográfica do rio da Cruz, mesorregião do sertão do Estado da Paraíba, semiárido brasileiro. Na metodologia utilizada, procedeu-se à delimitação da microbacia hidrográfica usando geotecnologias e posterior visita às propriedades rurais dos municípios nos quais a microbacia está circunscrita, bem como observações in loco e aplicação de questionários de diagnósticos socioeconômico e ambiental. Os resultados obtidos mostram os graus de deterioração dos respectivos diagnósticos, que foram de 53,46\% e 23,8\%. O grau de deterioração socioeconômico é preocupante, tendo em vista a suscetibilidade da região às variáveis climáticas e condições edáficas regionais, o que implica diretamente a condição social e qualidade de vida das populações locais. Por outro lado, a deterioração ambiental apresentou um valor moderadamente baixo, e o desafio futuro será a implementação de práticas agrícolas, de pecuária e/ou florestais que venham a contribuir para melhoria das condições socioeconômicas, sem o aumento do indicador de deterioração ambiental.

\section{Degree of socioeconomic and environmental deterioration as a tool for territorial management in a watershed}

\begin{abstract}
Under Brazilian law, the watershed is the territorial unit for implementation of the National Water Resources Policy. In this sense, the management of water resources, priceless to society, must be done using practices that maintain environmental balance and proper management of land use in watersheds, being essential for the maintenance of natural resources and society in general. This study aimed to determine deteriorating units in the watershed of the Rio da Cruz, a semi-arid mesoregion of the Paraiba State, Brazil. In the methodology used, the watershed was delimited using geotechnologies and subsequent visit to the rural properties of the municipalities where the watershed is circumscribed, as well as on-site observations and application of socioeconomic and environmental diagnostic questionnaires. The results show the degrees of deterioration of the respective diagnoses, which were $53.46 \%$ and $23.8 \%$. The degree of socioeconomic deterioration is of concern, given the region's susceptibility to climate variables and regional edaphic conditions, which directly implies the social condition and quality of life of local populations. On the other hand, environmental deterioration has been moderately low, and the future challenge will be the implementation of agricultural, livestock and/or forestry practices that may contribute to the improvement of socioeconomic conditions, without increasing the indicator of environmental deterioration.
\end{abstract}

Keywords: Diagnosis; Socioeconomic; Environmental; Brazilian semiarid.

Topic: Desenvolvimento, Sustentabilidade e Meio Ambiente

Reviewed anonymously in the process of blind peer.
Received: 02/10/2019

Approved: $26 / 11 / 2019$
João Batista Alves (iD)

Universidade Federal de Campina Grande, Brasil

http://lattes.cnpq.br/2775708005526266

http://orcid.org/0000-0002-1548-7996

alvesjb@uol.com.b

Luan Silva Figueroa (iD)

Universidade Federal de Campina Grande, Brasil

http://lattes.cnpq.br/0412745867091228

http://orcid.org/0000-0003-3795-2040

luan.figueroa@hotmail.com

Joedla Rodrigues Lima

Universidade Federal de Campina Grande, Brasil

http://lattes.cnpq.br/9739711047450380

http://orcid.org/0000-0001-6617-2858

joedlalima@yahoo.com.br
Referencing this:

ALVES, J. B.; FIGUEROA, L. S.; LIMA, J. R.. Grau de deterioração socioeconômico e ambiental como ferramenta para gestão territorial em uma microbacia hidrográfica. Revista Ibero Americana de Ciências Ambientais, v.10, n.6, p.287-301, 2019. DOI:

http://doi.org/10.6008/CBPC2179-6858.2019.006.0025 


\section{INTRODUÇÃO}

A sociedade humana depende quase que exclusivamente dos bens naturais para sua sobrevivência e, dentre os diversos recursos, pode-se destacar a água. A importância desse elemento é narrada em todos os povos e há exemplo de grandes civilizações que se ergueram tendo como base o uso da água em larga escala, na agricultura, a exemplo da ocupação das margens do rio Nilo pelos egípcios. Nesse contexto, Silva (2016) cita a afirmação do historiador Heródoto: 'O Egito é uma dádiva do Nilo'. Nessa conjuntura, pode-se reiterar que o Egito conseguiu o grau de sofistificação cultural da época cpm uma contribuição significativa do rio Nilo, e não o inverso, dadas as suas condições fisiográficas. Esse é apenas um dos inúmeros exemplos de povos que alcançaram proporções épicas ao nascerem e se desenvolveram às margens de rios, lagos e estuários.

Na contemporaneidade, não é diferente, pois as populações se concentram nas margens de rios, lagos e costas oceânicas. Nestas últimas, por exemplo, $26 \%$ da população brasileira se encontra assentada (IBGE, 2010). No entanto, essa concentração, aliada ao crescimento populacional, acaba contribuindo de forma significativa para a exaustão de recursos naturais, fragilizando o equilíbrio da relação sociedade e natureza, podendo provocar alterações bruscas e emergência de graves problemas socioambientais. Dentre esses problemas, Melo et al. (2016) mencionam que a utilização indevida dos recursos naturais em bacias hidrográficas desencadeia uma série de problemas que vão desde a contaminação dos mananciais até mudanças microclimáticas na região.

No Brasil, é possivel verificar diversos acontecimentos que mostram a realidade da gestão de recursos hídricos, a exemplo do que ocorreu recentemente com os rompimentos das barragens do Fundão e da mina do Córrego do Feijão, em Mariana/MG e Brumadinho/MG, respectivamente, que acabaram contaminando rios importantes para o desenvolvimento local e regional. Outro exemplo a citar é a intensa degradação e assoreamento que vem ocorrendo no Rio São Francisco, culminando na morte de nascentes, asssoreamento do leito do rio, prejudicando atividades produtivas e turísticas, dentre outras tantas (MOTTA et al., 2016).

Souza et al. (2015) apontam que, para entender o uso dos recursos naturais no cenário rural brasileiro, é necessária uma análise ecossocioeconômica, em que a preservação dos recursos se encaixe no contexto ambiental, social e econômico de utilização dos mesmos. Nesse sentido, ao tratar de questões hídricas, a Lei 9433, de 8 de dezembro de 1997, que estabeleceu a Política Nacional de Recursos Hídricos PNRH, cita, no artigo 10 inciso $V$, que "a bacia hidrográfica é a unidade territorial para implementação da Política Nacional de Recursos Hídricos e atuação do Sistema Nacional de Gerenciamento de Recursos Hídricos" (BRASIL, 1997).

Para implementar essa política, é preciso fazer planejamento e depois a gestão do sistema; contudo, para que isso ocorra, é preciso conhecer a relação entre os aspectos sociais, econômicos e ambientais da população residente nessas áreas, dentre outros. Tal aprendizagem é necessária para poder sugerir práticas sustentáveis que objetivem sanar eventuais problemas ambientais, melhorar as condiçoes de vida da 
população residente e, por conseguinte, melhoria do sistema ambiental da área. Nessa seara, o conhecimento dos problemas sociais e ambientais que assolam uma população é indispensável no processo de planejamento e investimento social, com vistas a reduzir fatores como a pobreza e a má distribuição da renda, que, historicamente, afligem diversas populações, entre elas, a população nordestina, em convivência constante com a escassez de água, com graves problemas de degradação.

A deterioração em territórios áridos e semiáridos, os quais se caracterizam por escassez de recursos, é resultado de diversos fatores ambientais, incluindo ainda práticas inadequadas de atividades antrópicas, que estão sempre à frente dos processos de degradação ambiental e perturbações sociais (FRANCO et al., 2005). Nesse sentido, Alves et al. (2009) mencionam que, no polígono das secas, encontram-se as maiores áreas de desertificação, devido ao uso inapropriado e inconsciente dos recursos naturais, fato este que tem movido diversas esferas da sociedade a buscar soluções que modifiquem esse quadro. Contudo, reverter o processo de degradação ambiental dos recursos naturais, no semiárido brasileiro, deve ser a primeira medida considerada em um programa de convivência com a seca. Rocha (1997) cita que, para isso, deve haver formas eficientes de monitoramento e fiscalização das bacias hidrográficas, para assegurar uma gestão eficiente dos recursos que as compõem e uma reformulação na concepção dos atuais projetos públicos voltados para essas questões.

Há inúmeras bacias hidrográficas no nordeste brasileiro carecendo de estudos sobre as condições socioeconômicas e ambientais que possam vir a contribuir para o processo implementação de políticas públicas que viabilizem a recuperação desses ambientes. Dentre as diversas bacias hidrográficas, uma das mais importantes do nordeste setentrional é a bacia hidrográfica rio Piranhas-Açu, de ordem federal, com $43683 \mathrm{~km}^{2}$. Nesta, encontra-se a sub-bacia do rio Espinharas, com $3291 \mathrm{~km}^{2}$. Nesse mesmo sentido, a subbacia do rio Espinharas é composta por inúmeros afluentes, entre eles, o rio da Cruz (ANA, 2016).

Verifica-se na região uma escassez de informações sobre a situação socioeconômica e ambiental das propriedades rurais, inseridas nos interstícios das microbacias. Dessa forma, o presente estudo procura responder qual o grau de deterioração socioeconômico e ambiental a que as populações destas microbacias estão submetidas. Para tal, o objetivo do trabalho foi realizar o diagnóstico socioeconômico e ambiental da microbacia rio da Cruz e estabelecer os graus de deterioração das respectivas variáveis, assim como sugerir um conjunto de medidas mitigatórias para atenuar as condições de sobrevivência da população e recuperação da microbacia, tendo em vista ser uma das principais contribuidoras de fornecimento de água para a sub-bacia.

\section{METODOLOGIA}

O rio da Cruz é uma microbacia localizada na mesorregião Sertão Paraibano e microrregião do município de Patos-PB, sendo seu exutório dentro da cidade de Patos, o mais importante polo econômico/educacional do sertão paraibano, com população estimada em 107.790 habitantes (IBGE, 2017). A microbacia está circunscrita nas seguintes coordenadas geográficas: $7^{\circ} 20^{\prime} 26,4^{\prime \prime}$ a $7^{\circ} 02^{\prime}$ 05,6" de latitude sul e $37^{\circ} 31^{\prime} 27,8^{\prime \prime}$ a $37^{\circ} 16^{\prime} 28,8^{\prime \prime}$ de longitude a oeste de Greenwich. O clima é caracterizado como semiárido 
quente BSh, de acordo com a classificação climática de Köppen, quente e seco, com pouco regime de chuvas, chegando a uma pluviosidade anual próxima a $800 \mathrm{~mm}$ e temperatura média anual em torno de 25 ㄷ C (LUCENA, 2015).

No seu exutório, funde-se com o rio Farinha, formando o rio Espinharas, os quais integraram a subbacia hidrográfica e, por conseguinte, a bacia hidrográfica do rio Piranhas-Açu, cuja nascente é no alto sertão do Estado da Paraíba, desaguando no oceano Atlântico, Estado do Rio Grande do Norte. Abrange completa e/ou parcialmente 147 municípios, onde vivem aproximadamente 1.552 .000 mil habitantes (ANA, 2016).

A microbacia Rio da Cruz, conforme a Figura 1, tem uma área de captação de 739,40 km², sendo $98 \%$ de sua área inserida no Estado da Paraíba, abrangendo os municípios de Imaculada, Mãe D'Água, Maturéia, Patos, Santa Terezinha, São José do Bonfim e Teixeira e 2\% nos municípios de Brejinho e Santa Terezinha, Estado de Pernambuco (MEDEIROS et al., 2017).

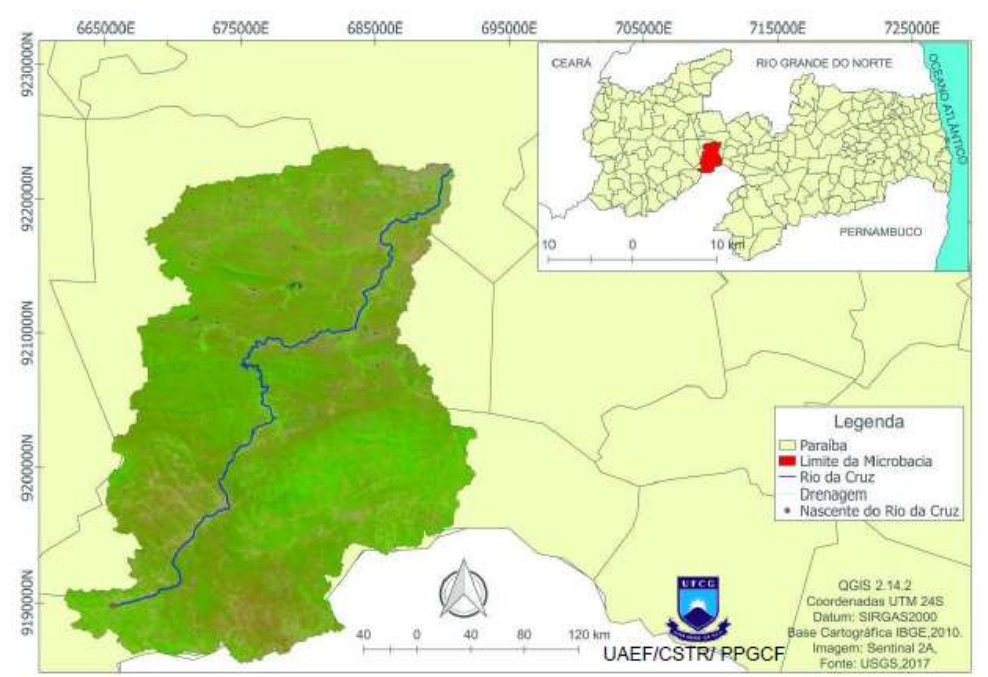

Figura 1: Mapa de localização da microbacia do rio da Cruz - PB/PE. Fonte: Anjos (2018).

\section{Coleta de dados}

O cálculo do número de propriedades rurais para a realização das entrevistas foi estabelecido a partir do número de residências rurais por município, proporcional à área da microbacia, em cada município, utilizando os dados do censo demográfico do IBGE (2010). Esses dados foram cruzados com as informações da área da microbacia georreferenciada, sendo obtido um total de 689 propriedades inseridas, que compreendem a área da microbacia rio da Cruz, como pode ser visualizado na Tabela 1. Para equacionar o número de entrevistados no campo, utilizou-se da equação proposta por Rocha (1997), a seguir:

$$
N=3,841 \cdot n \cdot 0,25 /\left[(0,1)^{2} \cdot(n-1)+3,841 \cdot 0,25\right]
$$

Em que:

$\mathrm{N}=$ número de visitas a serem feitas pelo pesquisador; 3,841 = valor tabelado proveniente do Qui - Quadrado; 0,25 = variância máxima para um desvio padrão de 0,5 ; $0,1=$ erro (10\%) escolhido pelo pesquisador; $\mathrm{n}=$ número total de propriedades na unidade considerada.

Conforme a equação proposta por Rocha (1997), o número de propriedades entrevistadas foi calculado se admitindo um erro de $10 \%$ recomendado pelo autor, chegando a um número mínimo de 85 
propriedades rurais a serem visitadas. Optou-se pela entrevista de 100 propriedades neste estudo. As propriedades foram visitadas durante o período de um ano, entre 2017 e 2018.

Tabela 1: Área da microbacia por munícipio e número de domicílios rurais entrevistados. Patos-PB 2018.

\begin{tabular}{|l|l|l|l|l|}
\hline \multicolumn{1}{|c|}{ Município } & Área $(\mathbf{K m})^{\mathbf{2}} \mathbf{( * )}^{\mathbf{*}}$ & Percentual de área (\%) & $\begin{array}{c}\mathbf{N}^{\circ} \text { de propriedades } \\
\left(\text { município) } \mathbf{( * )}^{*}\right.\end{array}$ & Propriedades por unidade de área \\
\hline Patos - PB & 77,14 & 10,43 & 645 & 68 \\
\hline Santa Terezinha - PB & 182,27 & 24,65 & 616 & 151 \\
\hline Mãe D'água - PB & 207,14 & 28,01 & 703 & 196 \\
\hline São José do Bonfim - PB & 69,63 & 9,41 & 491 & 46 \\
\hline Teixeira - PB & 55,20 & 7,46 & 1166 & 89 \\
\hline Maturéia - PB & 79,78 & 10,79 & 527 & 57 \\
\hline Imaculada - PB & 64,04 & 8,66 & 953 & 82 \\
\hline Santa Terezinha - PE & 0,56 & 0,09 & 1065 & 1 \\
\hline Brejinho-PE & 3,64 & 0,5 & 1071 & 1 \\
\hline Total & 739,40 & 100 & 7248 & 689 \\
\hline
\end{tabular}

Fonte: IBGE (2010).

\section{Diagnóstico socioeconômico e ambiental}

A geração dos dados da pesquisa foi obtida através da metodologia para microbacias proposta por Rocha (1997), a qual visa analisar o grau de deterioração socioeconômica e ambiental na microbacia. O método consiste numa série de perguntas em nível de produtor, incluindo visita e análise das condições da propriedade, por meio de questionários adaptados do Centro Interamericano de Desenvolvimento Integral de Águas e Terras (CIDIAT), compondo-se de variáveis ambientais, sociais, econômicas e tecnológicas.

Nessa metodologia, o fator socioeconômico é dividido em três fatores: o social, o econômico e o tecnológico, os quais são analisados isoladamente, na busca para determinar a deterioração para cada fator, sendo que, posteriormente, o somatório do valor modal dos três aspectos comporá a deterioração socioeconômica da microbacia Rio da Cruz.

O diagnóstico ambiental consiste em um questionário com perguntas diretas ao produtor, conforme proposto por Rocha (1997). Neste diagnóstico, levantaram-se todos os elementos poluentes do ambiente, de maneira direta. Nessa etapa, foram utilizados 21 indicadores de poluição ambiental, conforme o autor anteriormente citado. Cada fator analisado apresenta valores mínimos e máximos, assim como uma equação determinada para o cálculo da porcentagem de deterioração local, de acordo com Rocha (1997), distribuídos no Tabela 2.

Tabela 2: Fatores socioeconômicos e ambientais analisados, valores máximos, mínimos e equação definida. Patos. 2018

\begin{tabular}{|l|l|l|l|}
\hline \multicolumn{1}{|c|}{ Fatores } & \multicolumn{1}{c|}{ Mínimo } & \multicolumn{1}{c|}{ Máximo } & \multicolumn{1}{c|}{ Equação } \\
\hline Social & 51 & 287 & $\mathrm{y}=0,4237 \mathrm{x}-21,6053$ \\
\hline Econômico & 21 & 68 & $\mathrm{y}=2,1276 \mathrm{x}-44,6782$ \\
\hline Tecnológico & 17 & 52 & $\mathrm{y}=2,8571 \mathrm{x}-48,5700$ \\
\hline Socioeconômico & 89 & 407 & $\mathrm{y}=0,3145 \mathrm{x}-27,9982$ \\
\hline Ambiental & 21 & 42 & $\mathrm{y}=4,76 \mathrm{x}-99,96$ \\
\hline
\end{tabular}

Fonte: Adaptado de Rocha (1997).

O valor da deterioração, que proporcionou o conhecimento das unidades críticas de deterioração social, econômica, tecnológica e socioeconômica, foi atribuído a partir da equação da reta $y=a x+b$, em que $y=$ porcentagem de deterioração, variando de 0 a $100 \%$, e $x=$ valor significante encontrado em função das 
respostas aos questionários aplicados (ROCHA, 1997). As constantes apresentadas foram calculadas a partir dos valores mínimos e máximos de deterioração que seria teoricamente possível, variando entre 0 e $100 \%$, respectivamente.

O máximo de deterioração aceitável para cada fator analisado é de $10 \%$. Conforme assevera Rocha (1997), valores acima do recomendado indicam a necessidade de interferência humana para recuperação e equilíbrio da microbacia hidrográfica. Complementando a pesquisa, Rocha (1997) sugere ainda questionar junto aos produtores os três fatores enfrentados por eles que mais dificultam a sua produção e bem-estar. Tais fatores são priorizados em função do maior para o menor número de respostas.

\section{RESULTADOS E DISCUSSÃO}

\section{Diagnóstico socioeconômico}

Os valores de X encontrados para os fatores social, econômico, tecnológico e socioeconômico foram, respectivamente: 157; 56; 46 e 259. Estes fatores foram aplicados às suas respectivas fórmulas (Tabela 2) e encontrado os seguintes graus de deteriorações, respectivamente: 44,9; 74.47; 82,85 e 53,46. 0 diagnóstico socioeconômico que determina o grau de deterioração socioeconômica é dependente de um conjunto de variáveis avaliadas em nível de produtor rural que determinam as deteriorações: social, econômica e tecnológica, sendo totalmente moldado e fundamentado no somatório destas três variáveis.

No fator social, encontrou se um grau de deterioração de $44,9 \%$, sendo que, dentro do conjunto de variáveis deste indicador, as variáveis que mais contribuíram negativamente para o percentual encontrado foram: nível de instrução do produtor rural; média escolar dos atores sociais; total de pessoas por núcleo familiar e total geral de pessoas na propriedade.

O grau de escolaridade é um fator que contribui para que a propriedade seja utilizada ou não de forma racional, ou seja, com a utilização de técnicas de conservação. Tendo o produtor e as pessoas envolvidas no processo de produção da propriedade baixo grau de escolaridade, há a tendência de exploração insustentável dos recursos naturais. Aliado a isso, soma-se uma série de outros fatores, tais como a dificuldade de acesso ao crédito e a ineficiência do sistema público de extensão rural.

Por outro lado, seguindo os princípios da metodologia de Rocha (1997), quanto mais pessoas sobrevivem dependentes de uma mesma área, mais pressão sobre o ambiente ocorre e possibilidade de perda da sustentabilidade socioeconômica. Silva et al. (2017) comentam que as altas médias de pessoas por propriedade são estimuladas pelos altos índices de natalidade da população rural nordestina, isto é, pelas altas percentagens de crescimento vegetativo. Isso significa que ainda persiste, no local estudado, um preceito da família tradicional rural, cuja presença de um grande número de filhos contribuem para o trabalho familiar e, por conseguinte, sobrevivência da família, em contraposição àquilo preconizado pela metodologia utilizada neste estudo.

No que tange à deterioração econômica, encontrou-se um índice de $74,47 \%$, ou seja, um grau bastante elevado levando em consideração o grau de deterioração aceitável preconizado pela metodologia. 
As variáveis que mais contribuíram para esses valores foram: baixa produtividade das culturas implantadas; dificuldade de acesso ao crédito agrário; renda bruta produzida na propriedade e renda total do núcleo familiar menores que 5 salários mínimos mensais. Este grau de deterioração econômica indica a intensidade da dificuldade que o homem do campo, no semiárido, enfrenta para administrar sua propriedade e conduzila financeiramente.

Dentre os aspectos analisados, na produção, identificou-se que a atividade principal é a criação de gado bovino para corte, com produtividade baixa, além de aves e suínos em pequena escala, com venda em mercados e feiras locais ou para consumo próprio, predominando este último. Em relação às pastagens, verificou-se in loco que se caracterizavam como abandonadas. Isso se deve ao baixo regime pluviométrico da região, à falta de assistência técnica e à falta de acesso ao crédito agrícola, o que dificulta ainda mais a realização das atividades agropecuárias potenciais da região, como a criação de cabras, que são mais resistentes às condições ambientais. Por outro lado, a prática da agricultura ocorre somente no curto período de chuvas e com objetivos, quase sempre, para o consumo próprio.

Segundo Capobiango et al. (2012), o crédito agrário é um instrumento que fornece aos produtores os meios para exercerem um papel dinâmico na economia local. Nesse sentido, a restrição do crédito pode provocar consequências agravantes no meio rural, comprometendo o desenvolvimento do mesmo. De outra forma, a falta de crédito leva à falta de contratação de assistência técnica ou mesmo, se essa vier de forma gratuita pelos órgãos de governo, o produtor, muitas vezes, pela falta de recursos financeiros, não pode aplicar as técnicas recomendadas, o que pode explicar os resultados encontrados.

Esses fatores estão interligados e podem ser respaldados pela condição tecnológica apresentada pelos produtos da microbacia, cujo percentual de deterioração foi de $82,85 \%$, ou seja, um grau elevadíssimo de deterioração. Dentre as variáveis que mais contribuíram para a situação encontrada, estão: a falta de maquinário agrícola; a falta de agregação de valor ao que foi produzido, pela ausência de industrialização e/ou até mesmo produção artesanal; a falta de assistência técnica e, por conseguinte, do emprego de técnicas de conservação do solo.

O uso de irrigação também foi um fator que influenciou nos resultados negativos obtidos. Considerando a escassez de água durante a maior parte do ano, os produtores concentram suas atividades agrícolas durante período de chuvas, bastante concentrado, característico da região semiárida. Isso torna tênue a diferença entre a possibilidade de sucesso ou fracasso, na colheita, devido às altas variabilidades da distribuição espacial e temporal das chuvas. Na maioria das propriedades, os trabalhos são realizados manualmente ou com auxílio dos animais, tornando-os onerosos e desgastantes para os produtores rurais.

Ferreira et al. (2008) comentam que a ausência de maquinário agrícola implica menor capacidade de plantio e tratos culturais, reduzindo a capacidade de produzir nas propriedades. Diante dos fatos, confirmase a falta de assistência técnica rural por parte de órgão públicos e/ou similares, contribuindo assim para esse altíssimo grau de deterioração tecnológica. A problemática da assistência técnica rural no Brasil perpassa pela falta de constância no processo de estruturação das políticas públicas voltadas para essa questão. Se observar esse processo desde sua criação, na década de 40 , vai-se verificar uma série de 
mudanças nos programas de governo. Entende-se que, diante de tantas mudanças em função de governos que entram e saem, não há uma política consistente de estado. Castro et al. (2017) mencionam que os serviços de assistência técnica e extensão rural (Ater), no Brasil, tiveram início em 1948, com a criação da Acar em Minas Gerais. Daquele período até hoje, muita coisa mudou. Abramovay (1999) comentou que o Sistema Brasileiro de Assistência Técnica e Extensão Rural (SIBRATER) era marcado por contradições. $O$ autor expôs que, por um lado, existia, entre as associações, uma concordância no pensamento a respeito do compromisso em conduzir o extensionismo em busca do desenvolvimento socia; por outro lado, não se pode ter a mesma afirmação a respeito da gestão, das fontes de recursos e da coordenação institucional de todo o sistema de extensão.

Nesse contexto, é possível observar que o Sistema de Assistência Técnica e Extensão Rural sofre com problemas de caráter articulador e estrutural, mostrando-se insuficiente na assistência aos pequenos agricultores da região em estudo. Hoje, em relação à agricultura familiar, além da Lei n. 11.326/2006, que trata da Política Nacional de Agricultura Familiar e Empreendimentos Rurais Familiares, também vigora a Política Nacional de Assistência Técnica e Extensão Rural, Lei n. 12/188/2010 (BRASIL, 2010) e o decreto federal n. 8.252/2014, que trata da criação da Agência Nacional de Assistência Técnica e Extensão Rural (ANATER), que tem como função:

promover, estimular, coordenar e implementar programas de assistência técnica e extensão rural, visando à inovação tecnológica e à apropriação de conhecimentos científicos de natureza técnica, econômica, ambiental e social; promover a integração do sistema de pesquisa agropecuária e do sistema de assistência técnica e extensão rural; fomentar o aperfeiçoamento e a geração de novas tecnologias e a sua adoção pelos produtores; apoiar a utilização de tecnologias sociais e os saberes tradicionais utilizados pelos produtores rurais; contratar serviços de assistência técnica e extensão rural; promover a universalização dos serviços de assistência técnica e extensão rural para os agricultores familiares e os médios produtores rurais. (SILVA, 2016)

Landini (2014) afirma que há expressiva ausência de recursos humanos para desenvolver atividade de assistência técnica e extensão rural, o que provoca o assentamento de poucos profissionais na área de extensão em relação ao número de produtores que necessitam desses serviços, comprometendo toda a cadeia de atividades. Estudos desenvolvidos em outras bacias hidrográficas, assim como em assentamentos rurais sobre a deterioração tecnológica no semiárido paraibano, a exemplo de Pereira et al. (2009), Alves et al. (2012a) e Barros et al. (2014), encontraram percentuais de $64,42 \%, 78,21 \%$ e $66,18 \%$, respectivamente. Tais resultados mostram intensa deterioração tecnológica nas propriedades rurais inseridas no semiárido paraibano. Desta forma, os dados deste trabalho corroboram aqueles autores. Na Figura 2, observa-se o índice de deterioração socioeconômica na microbacia hidrográfica rio da Cruz. Foi encontrada uma porcentagem deterioração de 53,46\%. Este valor também está acima do valor máximo aceitável (10\%), conforme Rocha (1997).

Para o modelo de metodologia utilizada, os elevados índices de deterioração socioeconômica, como os calculados para a microbacia rio da Cruz, indicam que a população assentada enfrenta condições frágeis e instáveis de sobrevivência local. O valor obtido confirma os obtidos em outras áreas rurais no sertão paraibano, a exemplo do que encontraram Alves et al. (2012b), Silva et al. (2013) e Barros et al. (2014), cujos 
índices de deterioração socioeconômica foram, respectivamente, de 55,58\%, 41,00\% e 59,83\%.

Compreende-se que há necessidade de introduzir métodos e tecnologias que sejam capazes de atenuar pressões antrópicas no meio ambiental, que refletem diretamente no meio social, fundamentandose na premissa de que, quanto maior forem as dificuldades de sobrevivência no campo, maior será a possibilidade de ocorrer êxodo rural, culminando com o inchaço das cidades, esvaziamento do campo e agravando a frágil estabilidade econômica da região.

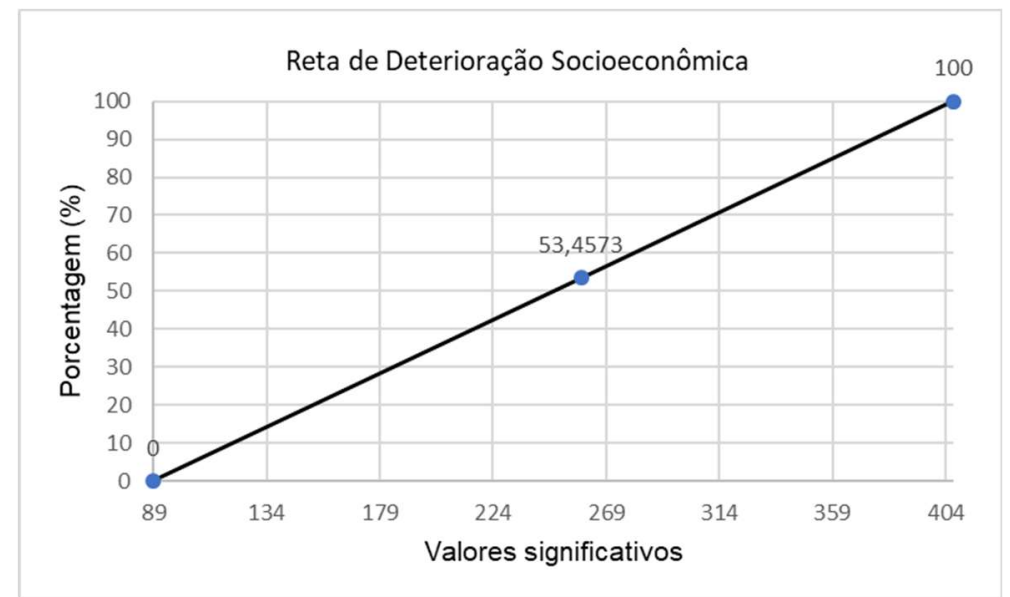

Figura 2: Deterioração socioeconômica calculada para a microbacia Rio da Cruz. Fontes: Patos (2018).

Pisani et al. (2011) evidenciaram que, no atual contexto, a falta de investimentos na agricultura familiar configura-se numa das maiores dificuldades enfrentadas no campo, o que resulta em obstáculos para obtenção de credito agrícola, assistência técnica precária ou inexistente para a produção e comercialização, culminando na desvalorização do pequeno produtor. Apesar das atividades agropecuárias representarem uma expressividade no arranjo da estrutura econômica da população rural, é importante destacar que incorporar novas práticas que possibilitem o aproveitamento dos recursos naturais locais, em equilíbrio com o ambiente, torna-se extremamente necessário na busca para reverter o atual quadro de degradação.

Ferreira et al. (2008) destacam que a ausência de aproveitamento do artesanato reduz a perspectiva de renda extra e ocupação da mão de obra feminina local, restringindo a renda do núcleo familiar às atividades tradicionais. Os autores chamam atenção para a ausência de beneficiamento de produtos agrícolas e animal, fato que diminui a possibilidade de uma renda extra e agregação de valor na produção.

Atividades dessa natureza, cuja instalação seja potencializada por meio de intervenções estimuladas por políticas públicas adequadas e direcionadas, podem fomentar a organização da sociedade civil e contribuir para a construção de ações sustentáveis de convivência com o semiárido e valorização cultural. Pode-se, citar como exemplo, o programa 'Um milhão de cisternas'. Se compararmos os três índices de deterioração apresentados, o social, o econômico e o tecnológico, verifica-se que o social foi o que apresentou menor índice. Uma hipótese explicativa que mereceria um estudo mais profundo é se houve atenuantes para este indicador, a partir dos programas sociais promovidos pelo Governo Federal nessa última década, o que pode ter contribuído para melhoria deste indicador. No entanto, os altos valores nos outros índices ainda mostram o grau de pobreza da população do campo, sua insegurança e suas dificuldades de, por si só, fazer mudanças significativas, que visem a um desenvolvimento sustentável (BARROS et al., 
2014).

Esse problema retrata a falta de execução eficiente das políticas públicas para o meio rural nordestino, pois há órgãos governamentais apoiadores, como a Política Nacional de Assistência Técnica e Extensão Rural (PNATER) e o Programa Nacional de Fortalecimento da Agricultura Familiar (PRONAF). Contudo, as populações rurais ainda sofrem com a falta de acesso a esses recursos, além de, historicamente, terem dificuldade de acesso às escolas nas áreas rurais brasileiras. Segundo o IBGE (2010), apenas 5\% das escolas rurais no Brasil possuíam rede de esgoto encanada, somente em $27 \%$ das escolas havia conexão com uma rede de água, e 15\% não apresentavam qualquer estrutura para lidar com resíduos sólidos. Esses dados comprovam que a população rural brasileira ainda se encontra em um processo de exclusão e vulnerabilidade social.

\section{Diagnóstico Ambiental}

Para o diagnóstico ambiental cuja fórmula explicita na tabela 2, o valor encontrado foi de 42, que aplicado à referida fórmula se tem o grau de deterioração ambiental de $23,8 \%$. No que concerne ao fator ambiental da microbacia rio da Cruz, o valor significativo encontrado e apresentado na Figura 3, indica uma unidade crítica de deterioração de $23,8 \%$, o que é bastante reduzido e significativo em relação aos outros índices, embora, seja de consenso entre diversos autores, como por exemplo: Rocha (1997), Pereira et al. (2009), Hernandes et al. (2010) e Alves et al. (2011), está acima do recomendado, portanto é necessário um projeto integrado de manejo de bacia hidrográfica, através de prognósticos, que visem à recuperação total do ambiente.

O fator ambiental foi influenciado pelos elementos poluentes presentes nas propriedades que não recebiam orientação técnico-científica: lixeiros (lixo urbano ou rural), pocilgas, aviários, esgotos (fossas ou liberação de dejetos ao ar livre) e manuseio de bombas de recalque de água. Segundo a Agência Executiva de Gestão das Águas do Estado da Paraíba - AESA (2012), o espaço do semiárido da Paraíba aparece como um dos mais afetados pela degradação dos recursos naturais comparado, a outros estados. Tal constatação se deve, em muito, à exploração agropecuária, principal fonte econômica da região. Contudo, o indicador de deterioração ambiental inclui variáveis a respeito da poluição ambiental da micro-bacia hidrográfica, que contribui para degradação da mesma, mas não tanto quanto outras ações como o desmatamento, o cultivo sem práticas de conservação do solo, entre outras.

Fica explícito que, na microbacia rio da Cruz, a ambiência encontra-se em um processo de deterioração ambiental moderada, contudo, devido à alta suscetibilidade à degradação do ambiente na região semiárida, este índice deteriorante pode romper a barreira da resiliência ecológica, segundo a metodologia utilizada, não sendo possível, portanto, retomar ao seu equilíbrio inicial sem que recursos humanos e financeiros sejam investidos. Logo, é necessária a admissão de medidas e práticas para conservação do solo dessas áreas e sua correta aplicação para a manutenção das funções ecológicas e socioeconômicas desses recursos a longo prazo. 


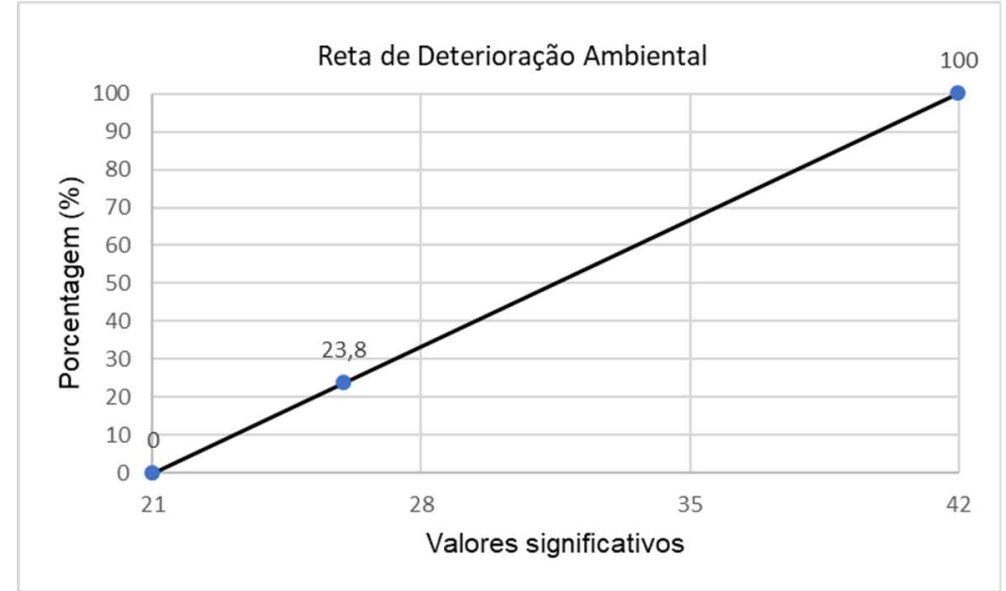

Figura 3: Deterioração ambiental calculada para a microbacia Rio da Cruz.

Além da necessidade de medidas sociais e ambientais de caráter emergencial local, é essencial rever o papel e o envolvimento das autoridades públicas no processo de gestão e manutenção dos recursos hídricos no espaço territorial estudado. Os problemas aqui constatados são recorrentes no semiárido brasileiro, devem ser reparados na sua origem e, para isso, é necessário se empenhar na conscientização no campo instrutivo para que os mesmos distúrbios sejam sanados e não voltem a acontecer. Além disso, há a necessidade de um planejamento para a exploração de atividades potenciais regionais e um plano de mitigação de impactos nos corpos hídricos.

\section{Contribuição para gestão territorial}

Baseado nos valores de deterioração encontrados para a microbacia rio da Cruz, recomenda-se para a população inserida na área de estudo a implementação de práticas de conservação e sustentabilidade para o meio rural, como: plantio em curvas de nível, controle de queimadas, recuperação de pastagens, adubação orgânica, práticas de conservação do solo, recuperação de áreas degradadas e reflorestamentos com espécies nativas.

Foi sollicitado aos entrevsitados que elencassem, em ordem de prioridade, os três fatores que mais os impedia de obterem o sucesso econômico e social na propriedade. Segundo eles, a falta de água, falta de crédito e pouca terra são determinantes e uma barreira para uma maior produção e estabilidade social. Nesse mesmo sentido, Alves et al. (2012a), estudando assentamentos rurais no Estado da Paraíba/PB, encontraram três outras dificuldades que os atores sociais enfrentavam, sendo eles: a falta de assistência médica/odontológica, de água e de apoio técnico. Desta forma, confirma-se que as políticas públicas ainda não conseguiram atingir os objetivos para que foram criadas.

Em resposta à falta de água agravada pela seca, diversas medidas já foram tomadas e tiveram êxito local, como a construção de açudes, e vêm sendo implementadas para mitigar os impactos que a escassez de água causou à população no semiárido nordestino. Dentre essas novas ações, Alves et al. (2012b) mencionam que "recentemente, a criação de políticas públicas voltadas a amenizar tal situação mostrou que é possível conviver com o semiárido". Os autores citam como exemplo o armazenamento de águas 'através das cisternas de placas, que é uma forma viável para captar e armazenar água de chuva, possibilitando a 
convivência nessas regiões atingidas pela seca'. Vale salientar que o programa denominado 'Um milhão de cisternas' é uma iniciativa da sociedade civil organizada, que teve apoio do poder público, pelo sucesso que vem obtendo.

No semiárido nordestino, políticas como essas foram e estão sendo empregadas, mostrando-se eficientes durante curtos períodos de seca. Em diagnósticos realizados no sertão paraibano, Alves et al. (2012a) e Sarmento et al. (2017) constataram que a população tem usado as cisternas placas, poços amazonas, açudes e poços artesianos como fontes principais de armazenamento de água.

Entretanto, em períodos de longas secas, apenas o armazenamento torna-se insuficiente para o produtor rural manter suas atividades econômicas estáveis. Sendo assim, inovações tecnológicas tornam-se necessárias para a manutenção do homem no meio rural. Com isso, abrem-se as portas para técnicas de convívio com o semiárido, especificamente projetos que visem à eficiência e economia de água, bem como à irrigação.

Nesse contexto, diversos avanços tecnológicos estão sendo colocados em prática no setor agrícola nos últimos anos. Países que passam períodos com escassez de água, como Israel, desenvolveram diversas soluções tendo como cenário o desperdício, por meio do emprego de técnicas de irrigação mais eficientes, como o gotejamento (SZUSTER, 2014).

A tecnologia de gotejamento torna-se uma técnica eficaz e acessível aos pequenos produtores sertanejos. O sistema pode ser feito com canos de PVC ou garrafas PET, barateando os custos e melhorando a produção. Este modelo de irrigação, aliado ao programa de cisternas em implementação, pode contribuir para solucionar os problemas de escassez de água na microbacia Rio da Cruz.

No que se refere à ausência de crédito agrário, desde a Lei 4.829/65, que institucionalizou o crédito rural, o país tem estabelecido uma política de crédito para o setor rural; contudo, Oliveira (2016) comenta que o setor agrícola brasileiro sofreu com os reflexos da crise financeira mundial iniciada em 2007, por conta da diminuição dos recursos disponibilizados ao seu fomento, seja para custeio ou para investimento. Por outro lado, o que se observa são fortes investimentos de crédito no agronegócio, o que, de certa forma, é bom para as exportações, em detrimento da agricultura familiar, que recebe parcos recursos, mas que é responsável por parcela significativa do abastecimento interno.

Nesse contexto, as cooperativas agropecuárias podem surgir como um auxílio aos sertanejos sem condições de acessar o crédito agrário, já que estas são formadas por produtores rurais que apresentam objetivos em comum e buscam melhores condições de preços e venda de seus produtos. São geralmente formadas por produtores vizinhos, que já possuem vínculos e afinidades, e têm o convívio constante.

A presença do cooperativismo e a boa relação entre os cooperados podem auxiliar produtores rurais em situações de vulnerabilidade em momentos específicos, com o fornecimento de crédito e empréstimos entre os membros. Além disso, Ferreira et al. (2008) recomendam a diversificação da produção agrícola e pecuária, pois a desvalorização nos preços de uma atividade ou cultura conseguiria ser balanceada em outra, fazendo com que o produtor rural tenha uma variedade de produtos a oferecer, mantendo um capital de giro necessário e, como estímulo, devem-se procurar cursos de capacitação para exploração de novas 
tecnologias para o meio rural.

No que concerne à pouca terra para produção, recomenda-se a união de atividades com o potencial de exploração na região, a exemplo dos sistemas agropastoris ou agrossilvopastoris. Cazella et al. (2009) comentam que, devido à multifuncionalidade dos sistemas agroflorestais, estes apresentam-se com uma percepção de 'novo olhar' sobre a agricultura familiar, pois possibilitam maior pluralidade de produtos e o emprego de uma atividade de exploração na mesma área.

Teixeira et al. (2015) apresentam resultados concretos dessa experiência no semiárido e citam exemplo de um assentamento rural na cidade de Ouricuri, no sertão pernambucano, onde cerca de $90 \%$ dos alimentos consumidos pelos produtores eram provenientes de SAF's. As autoras manifestam ainda que os agricultores conseguem, em uma mesma área, produzir uma diversidade de alimentos, tanto para a família como para os animais. Esse fator diminui a necessidade de mão de obra, evita fazer intervenção em outras áreas da propriedade, conservando assim ambientes importantes para o equilíbrio do sistema produtivo.

Fica evidente que a necessidade de mais terras não se torna um empecilho para a produção ao longo da microbacia rio da Cruz, pois o conhecimento e aprimoramento de algumas técnicas, por parte dos produtores, poderá promover uma melhora significativa na qualidade de vida da população local. Nesse sentido, indica-se que programas de assistência técnica e extensão rural devem ficar atentos a essas possibilidades e apresentá-las ao homem do campo. Na tabela 3, estão apresentadas as características encontradas na área de estudo e o que a população deve buscar para melhorar suas condições e superar limitações.

Tabela 3: Potencial, limitações e deteriorações analisadas na microbacia Rio da Cruz.

\begin{tabular}{|c|l|l|l|}
\hline Fator & Deterioração & \multicolumn{1}{|c|}{ Limitações } & \multicolumn{1}{c|}{ Potenciais } \\
\hline Socioeconômico & $53,46 \%$ & $\begin{array}{l}\text { Falta de crédito, escassez de água, produção } \\
\text { baixa, falta de mercado, assistência técnica, } \\
\text { produto pouco valorizado. }\end{array}$ & $\begin{array}{l}\text { Acessibilidade aos produtos, culturas anuais, } \\
\text { potencial agropecuário, } \\
\text { produtos nadeireiros, facilidade de negociações. }\end{array}$ \\
\hline & & $\begin{array}{l}\text { Conflito de uso da terra, baixa precipitação, } \\
\text { solos rasos, poluição, descarte inadequado energético e alimentação animal, rápida } \\
\text { de esgoto e resíduos sólidos. }\end{array}$ & $\begin{array}{l}\text { Solos férteis, vegetação com potencial } \\
\text { enegeneração de espécies nativas. }\end{array}$ \\
\hline
\end{tabular}

Fontes: Patos (2018).

\section{CONCLUSÕES}

A partir dos resultados obtidos, constatou-se um grau de deterioração socioeconômico acima do máximo recomendado (10\%), de acordo com a metodologia empregada, e uma moderada deterioração ambiental. Os dados demonstram um quadro preocupante tendo em vista fragilidade socioeconômica encontrada. Contudo, ambos os fatores requerem ações de interferência nas ações antrópicas, no sentido de mitigar as externalidades negativas do ponto de vista social, econômico e ambiental. Esses resultados indicam que se faz necessária a intervenção do poder público e/ou sociedade organizada para que, de forma articulada, possam empregar ações direcionadas para solução dos problemas identificados.

A sociedade deve se articular por meio dos seus representantes, em busca de parcerias e capacitação nas universidades, ATER's e ONG's locais, que visem à extensão rural, educação ambiental e assistência técnica de forma contínua, no sentido de incorporação das medidas mitigadoras recomendadas neste 
estudo, com a finalidade de aliviar pressões socioeconômicas e ambientais na microbacia Rio da Cruz. O grande desafio é melhorar (diminuir) o grau de deterioração socioeconômica sem aumentar o grau de deterioração ambiental, embora este esteja acima do recomendado, está se apresentando de forma moderada.

\section{REFERÊNCIAS}

ABRAMOVAY, R.. Agricultura familiar e serviço público: novos desafios para a extensão rural. Cadernos de Ciência e Tecnologia, Brasília, v.15, n.1, p.137-157, 1999.

AESA. Agência Executiva de Gestão das Águas do Estado da Paraíba. Caracterização de Regiões Naturais. João Pessoa: AESA, 2012.

ANA. Agência Nacional de Águas. Plano de recursos hídricos do rio Piancó-Piranhas-Açu: Resumo executivo. Brasília: ANA, 2016.

ALVES, D. F. S.; SILVA, D. D. E.; ANDREDE, S. R.; SOUSA, J. E.; MELO, M. S.; NOBREGA, J. E.. Análise do processo de armazenamento de água de chuva em cisternas de placas e sua utilização no município de Tavares, estado da Paraíba. In: CONEPI - CONGRESSO NACIONAL DE EDUCAÇÃO E PRÁTICAS INTERDISCIPLINARES, 7. Anais. Palmas, 2012a.

ALVES, J. B.; ALVES, A. R.; CONTANI, M. L.; NETO, J. A. M. Risco de vulnerabilidade em assentamentos rurais no estado da paraíba. Boletim centro de letras e ciências humanas, Londrina, v.63, p.231-262, 2012b.

ALVES, J. J. A.; SOUSA, E. N.; NASCIMENTO, S. S.. Núcleos de desertificação no estado da paraíba. Revista RA e GA, Curitiba, n.17, p.139-152, 2009.

ALVES, T. L. B.; ARAUJO, A. L.; ALVES, A. N.; FERREIRA, A. C.; NOBREGA, J. E.. Diagnóstico ambiental da microbacia hidrográfica do Rio do Saco, Santa Luzia/PB. Revista Brasileira de Geografia Física, Recife, v.2, n.1, p.396-412, 2011.

ANJOS, D. M.. Análise espaço: temporal do uso e cobertura do solo na microbacia do Rio da Cruz da região do semiárido na Paraíba, utilizando sensoriamento remoto. Dissertação (Mestrado em Ciências Florestais) - Universidade Federal de Campina Grande, Patos, 2018.

BARROS, J. D. S.; CHAVES, L. H. G.; FARIAS, S. A. R. Microbacia hidrográfica do riacho Val Paraíso: análise socioeconômica. Holos, Natal, v.30, n.4, p.34-46, 2014.

BRASIL. Lei n. 9.433 de 8 de janeiro de 1997. Institui a Política Nacional de Recursos Hídricos, cria o Sistema Nacional de Gerenciamento de Recursos Hídricos. Brasília: DOU, 1997.

BRASIL. Lei n. 12.188, de 11 de janeiro de 2010. Institui a Política Nacional de Assistência Técnica e Extensão Rural para a Agricultura Familiar e Reforma Agrária - PNATER e o Programa Nacional de Assistência Técnica e Extensão Rural na Agricultura Familiar e na Reforma Agrária - PRONATER. Brasília: DOU, 2010.
CAPOBIANGO, R. P.; BRAGA, M. J.; SILVEIRA, S. F. R.; COSTA, C. C. M.. Análise do impacto econômico do édito rural na microrregião de Pirapora. Revista de Economia e Sociologia Rural, Brasília, v.50, n.4, 2012.

CASTRO, C. N.; PEREIRA, C. N.. Agricultura Familiar, assistência técnica e extensão rural e a política nacional de Ater. Rio de Janeiro: IPEA, 2017.

CAZELLA, A. A. P.; BONNAL, P.; MALUF, R. M.. Agricultura familiar: multifuncionalidade e desenvolvimento territorial no Brasil. Rio de Janeiro: Mauad X, 2009.

FERREIRA, A. C.; TRAVASSOS, K. D.; LOPES, R. M. B. P.; FORMIGA, M. S.; RACHED, S. A.; BARACUHY, J. V. G.; SILVA, M. B. R.. Diagnóstico socioeconômico da microbacia hidrográfica do município de São José do Sabugi, PB. Revista Educação Agrícola Superior, Brasília, v.23, n.1, p.101-104, 2008.

FRANCO, E. S.; LIRA, V. M.; PORDEUS, R. V.; LIMA, V. L. A.; NETO, J. D.; AZEVEDO, C. A. V.. Diagnóstico socioeconômico e ambiental de uma microbacia no município de Boqueirão/PB. Engenharia ambiental, Espírito Santo do Pinhal, v.2, n.1, p.100-114, 2005

HERNANDES, J. F. M.; SCHMIDT, V.; MACHADO, J. A. D.. Impacto ambiental da suinocultura em granjas de porte médio a excepcional no vale do Taquari/RS. Revista de Gestão Social e Ambiental, São Paulo, v.4, n.3, p.18-31, 2010.

IBGE. Instituto Brasileiro de Geografia e Estatística. Censo 2010. Rio de Janeiro: IBGE, 2010.

IBGE. Instituto Brasileiro de Geografia e Estatística. v4.3.8.18.1. Patos: IBGE, 2017.

LANDINI, F. P.. Problemas enfrentados por extensionistas rurais brasileiros e sua relação com suas concepções de extensão rural. Ciência Rural, Santa Maria, v.45, n.2, 2014. DOI: http://dx.doi.org/10.1590/0103-8478cr20140598

LUCENA, D.. Patos de todos os tempos: A Capital do Sertão da Paraíba. João Pessoa: A União, 2015.

MEDEIROS, F. S.; ANJOS, D. M.; AZEVEDO, A. L.; LIMA, J. R. Caracterização morfométrica da microbacia do rio da Cruz localizada no semiárido do nordeste do Brasil. In: SIMPÓSIO BRASILEIRO DE RECURSOS NATURAIS DO SEMIÁRIDO SBRNS, 3. Anais. Fortaleza, 2017.

MELO, I. S.; SILVA, D. B.; SANTOS, A. L. A.; SANTANA, F. S.; SANTANA, B. L. P.. Atividade antrópica e degradação 
ambiental na sub-bacia hidrográfica Itamirim/SE. Revista REGNE, Natal, v.2, p.435-442, 2016.

MOTTA, E. J. O.; GONÇALVES, N. E. W.. Nascente do São Francisco: plano de preservação e recuperação das nascentes da bacia do rio São Francisco. Brasília: CODVASF, 2016.

OLIVEIRA, C. O.. Os Impactos da Crise Financeira Mundial no PRONAF. Revista RAGC, Monte Carmelo, v.4, n.9, p.112-124, 2016.

PEREIRA, R. A.; BARBOSA, M. F. N.. Diagnóstico socioeconômico e ambiental de uma microbacia hidrográfica no semiárido paraibano. Engenharia Ambiental. Espírito Santo do Pinhal, v.6, n.1, p.137-153, 2009.

PISANI, R. J.; GONÇALVES, S.; PERUSI, M. C.; CAMPOS, S.. Diagnostico socioeconômico e ambiental como ferramenta de planejamento para a agricultura familiar. Estudo de caso: sub-bacia do rio das pedras, Itatinga/SP. Revista Caminhos de Geografia, Uberlândia, v.12, n.40, p.70-79, 2011.

ROCHA, J. S. M.. Manual de projetos ambientais. Santa Maria: Imprensa Universitária, 1997.

SARMENTO, M. I. A.; NOBREGA, E. P.; OLIVEIRA, P. R. R.; SILVA, O. F.; PEREIRA JUNIOR, E. B.. Água da chuva: alternativa para convivência no semiárido. In: CONGRESSO MERCOSUL DE CATÁLISE, 9. Anais. Rio Lago, 2017.
SILVA, D. C.; BARACUHY, J.; CURI, W. F.; CUNHA, T. P. S. Diagnóstico socioeconômico e ambiental em uma área susceptível a desertificação: Estudo de caso da microbacia Riacho do Trapiá - Rio Grande do Norte - Brasil. Revista Espacios, Caracas, v.38, n.3, p.18, 2017.

SILVA, D. D. C.; MATTOS, A.. Diagnóstico socioeconômico e ambiental em microbacia hidrográfica localizada em um núcleo de desertificação. Revista caminhos de Geografia, Uberlândia, v.14, n.45, p.45-53, 2013.

SILVA, M. C.. Educação ambiental: ética, cidadania e sustentabilidade. In: ENCONTRO AMBIENTAL DE JI PARANÁ, 2. Anais. Porto Velho, 2016. p.5-22.

SILVA, R. O. P.. Assistência técnica e extensão rural no Brasil: um pouco de sua história. IEA, v.5, n.11, p.6, 2016.

SOUZA, L.; FLORIT, L. F.; MARTINS, L. H. S.. A

multifuncionalidade e a interdisciplinaridade e seus reflexos no processo de desenvolvimento do espaço rural. In: SEMINÁRIO INTERNACIONAL SOBRE DESENVOLVIMENTO REGIONAL, 7. Anais. UNISC, 2015.

SZUSTER, A.. O país da água. Conexão Israel: Ciência, Tecnologia, Meio Ambiente e Sociedade, 2014.

TEIXEIRA, C. T. M.; SILVA, T. C.. Agrofloresta e multifuncionalidade no Sertão de Pernambuco, Brasil. In: CONGRESSO LATINOAMERICANO DE AGROECOLOGIA. Anais. La Plata, 2015.

A CBPC - Companhia Brasileira de Produção Científica (CNPJ: 11.221.422/0001-03) detém os direitos materiais desta publicação. Os direitos referem-se à publicação do trabalho em qualquer parte do mundo, incluindo os direitos às renovações, expansões e disseminações da contribuição, bem como outros direitos subsidiários. Todos os trabalhos publicados eletronicamente poderão posteriormente ser publicados em coletâneas impressas sob coordenação da Sustenere Publishing, da Companhia Brasileira de Produção Científica e seus parceiros autorizados. Os (as) autores (as) preservam os direitos autorais, mas não têm permissão para a publicação da contribuição em outro meio, impresso ou digital, em português ou em tradução. 